Corrigendum

\title{
Corrigendum to "Wingless-Type MMTV Integration Site Family Member 5a Is a Key Secreted Islet Stellate Cell-Derived Product that Regulates Islet Function"
}

\author{
Wei Xu, ${ }^{1,2,3}$ Jun Liang $\mathbb{D}^{1},{ }^{1}$ H. F. Geng, ${ }^{1}$ Jun Lu ${ }^{1},{ }^{4}$ Rui Li, ${ }^{1}$ X. L. Wang, ${ }^{1}$ Qian Lv, ${ }^{1}$ Ying Liu, ${ }^{1}$ \\ Jie Wang, ${ }^{1}$ X. K. Liu, ${ }^{1}$ Peter M. Jones $\left(\mathbb{1},{ }^{2}\right.$ and $\mathrm{Zl}$ Sun $\mathbb{1}^{3}$ \\ ${ }^{1}$ Department of Endocrinology of Xuzhou Central Hospital, Xuzhou Institute of Medical Sciences, \\ Affiliated Hospital of Southeast University, Xuzhou, Jiangsu, China \\ ${ }^{2}$ Department of Diabetes, School of Life Course Sciences, King's College London, Guy's Campus, London, UK \\ ${ }^{3}$ Department of Endocrinology, Zhongda Hospital, Institute of Diabetes, Medical School, Southeast University, Nanjing, China \\ ${ }^{4}$ Key Laboratory of Biotechnology on Medicinal Plants of Jiangsu Province, School of Life Science, Jiangsu Normal University, \\ Xuzhou, China
}

Correspondence should be addressed to Peter M. Jones; peter.jones@kcl.ac.uk and Zl Sun; sunzilin1963@outlook.com

Received 24 September 2019; Accepted 30 September 2019; Published 23 October 2019

Copyright (C) 2019 Wei Xu et al. This is an open access article distributed under the Creative Commons Attribution License, which permits unrestricted use, distribution, and reproduction in any medium, provided the original work is properly cited.

In the article titled "Wingless-Type MMTV Integration Site Family Member 5a Is a Key Secreted Islet Stellate CellDerived Product that Regulates Islet Function" [1], the keys of Figures 1(b) and 3(a) were missing. The correct Figures 1 and 3 are shown below.

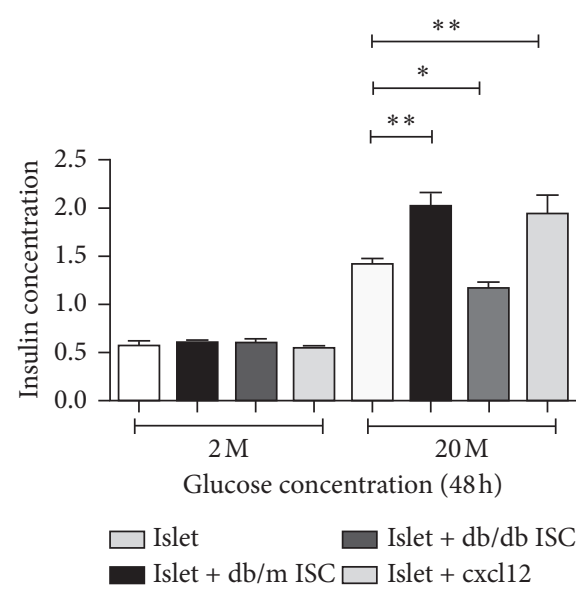

(a)

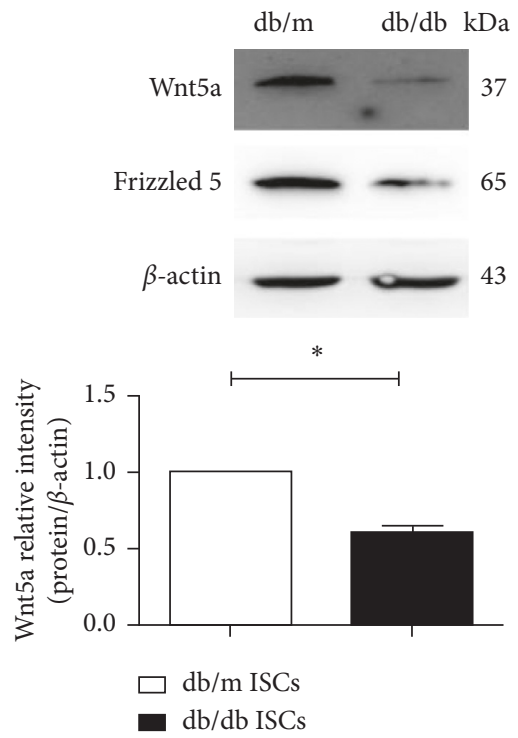

(b)

Figure 1: Continued. 


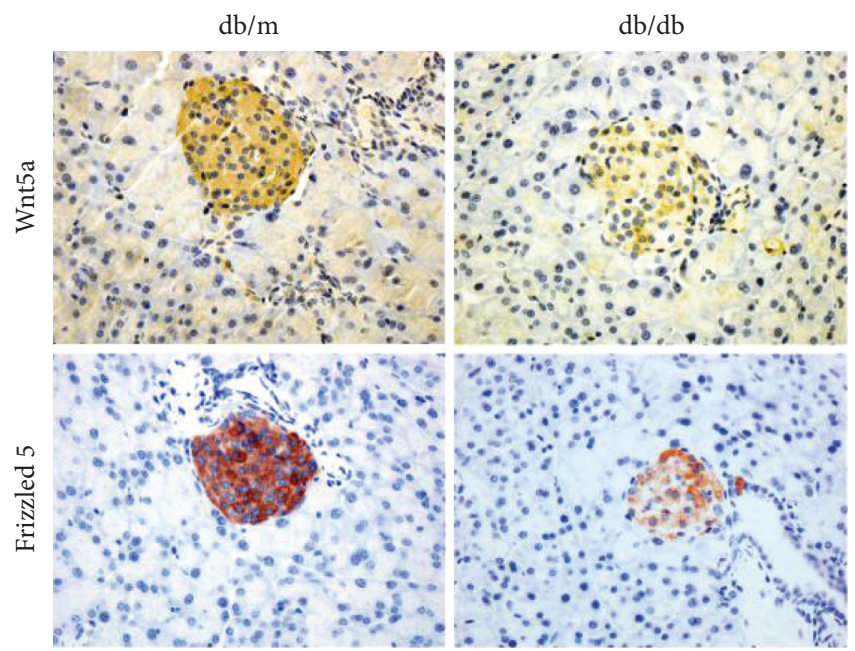

(c)

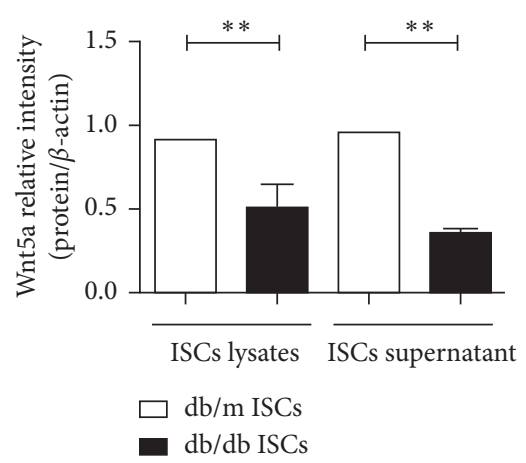

(d)

FIGURE 1: The effects of different ISC profiles on islet insulin secretory function and Wnt5a content and release by ISCs. (a) Compared with coculture with ISCs isolated from normoglycemic $\mathrm{db} / \mathrm{m}$ mice, coculture of islets with ISCs isolation from $\mathrm{db} / \mathrm{db}$ mice significantly reduced insulin secretion in vitro. All data were expressed as the mean $\pm \mathrm{SE}(n=3)$; ${ }^{*} P<0.05 ;{ }^{* *} P<0.01$; normoglycemic db/m ISCs vs hyperglycaemic $\mathrm{db} / \mathrm{db}$ ISCs. (b) Protein levels of Wnt5a were increased in control $\mathrm{db} / \mathrm{m}$ ISCs than $\mathrm{db} / \mathrm{db}$ ISCs. All data were expressed as the means \pm SE $(n=3) ;{ }^{*} P<0.05 ;{ }^{* *} P<0.01$; normoglycemic $\mathrm{db} / \mathrm{m}$ ISCs compared with hyperglycaemic db/db ISCs. (c) Wax-embedded sections of $\mathrm{db} / \mathrm{m}$ and $\mathrm{db} / \mathrm{db}$ mouse pancreases showing the expression of Wnt5a and Frizzled 5 as revealed by immunohistochemistry. Scale $\mathrm{bar}=50 \mu \mathrm{m}$. (d) Protein levels of Wnt5a were increased in $\mathrm{db} / \mathrm{m}$ ISCs lysates and supernatant than in the db/db ISCs. All data were expressed as the means \pm SE $(n=3) ;{ }^{*} P<0.05 ;{ }^{* *} P<0.01$; normoglycemic $\mathrm{db} / \mathrm{m}$ ISCs compared with hyperglycaemic $\mathrm{db} / \mathrm{db}$ ISCs.

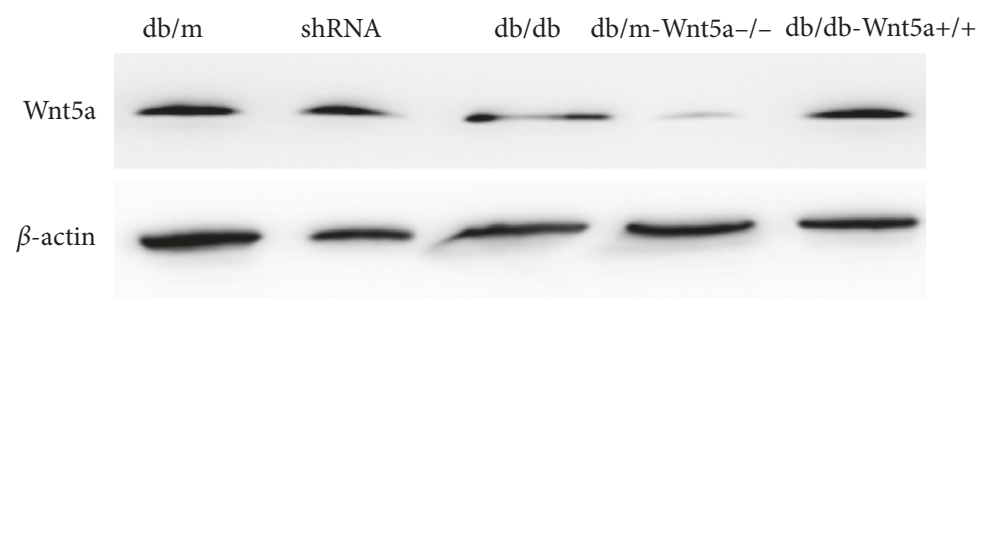

(a)

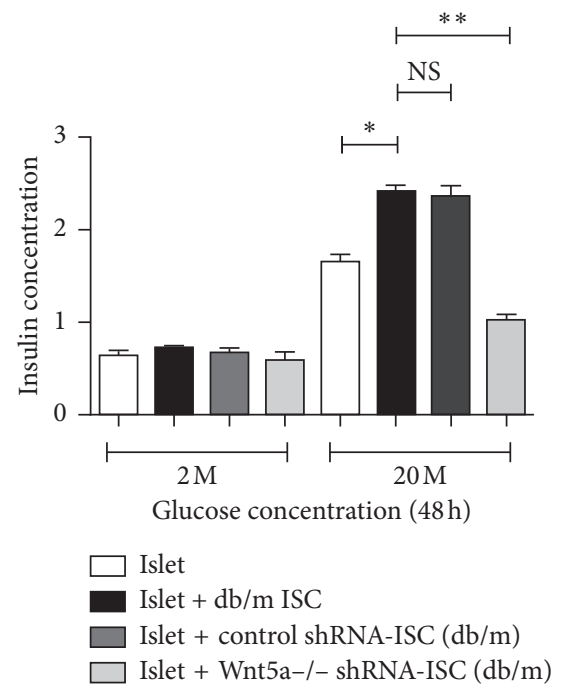

(b)

FIgURE 3: Continued. 


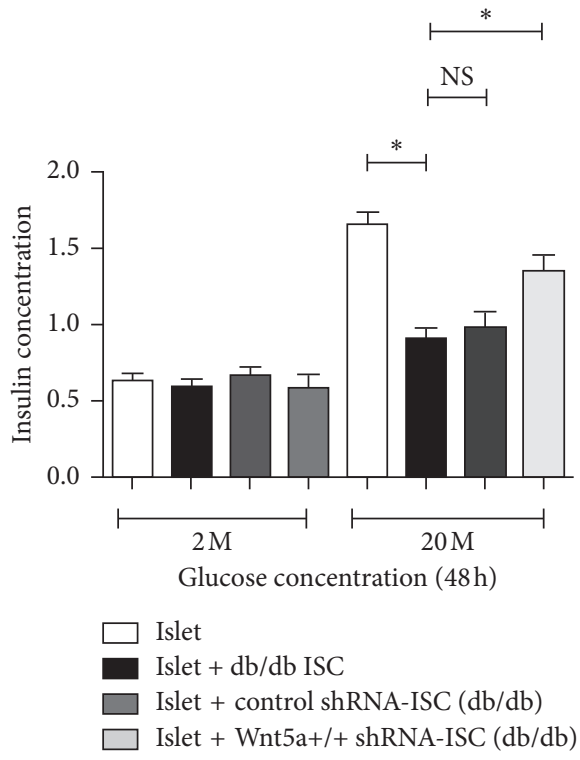

(c)

FIgURE 3: Wnt5a protein is a key modulator of ISC-mediated regulation of islet function. (a) A significant change in the mRNA expression of Wnt5a at 72 hours was caused by transfection of ISCs with shRNAs directly targeting Wnt5a when compared to control. All data were expressed as the means \pm SE $(n=3) ;{ }^{*} P<0.05$; ${ }^{* *} P<0.01$; shRNA Wnt5a-ISCs vs ISCs transfected with control nontargeting shRNAs. (b) Islets cocultured with Wnt5a-l- db/m ISCs had significantly reduced insulin secretion compared with control. All data were expressed as the means \pm SE $(n=3) ;{ }^{*} P<0.05 ;{ }^{* *} P<0.01$; shRNA Wnt $5 \mathrm{a}-1-\mathrm{db} / \mathrm{m}$ ISCs vs $\mathrm{db} / \mathrm{m}$ ISCs transfected with control nontargeting shRNAs. (c) The shRNA-induced upregulation of Wnt5a expression in hyperglycaemic $\mathrm{db} / \mathrm{db}$ ISCs increased the insulin secretion compared with the control. All data were expressed as the means \pm SE $(n=3) ;{ }^{*} P<0.05 ;{ }^{* *} P<0.01$; shRNA Wnt5a $+/+\mathrm{db} / \mathrm{db}$ ISCs vs $\mathrm{db} / \mathrm{db}$ ISCs transfected with control nontargeting shRNAs.

\section{References}

[1] W. Xu, J. Liang, H. F. Geng et al., "Wingless-type MMTV integration site family member $5 \mathrm{a}$ is a key secreted islet stellate cell-derived product that regulates islet function," International Journal of Endocrinology, vol. 2019, Article ID 7870109, 8 pages, 2019. 


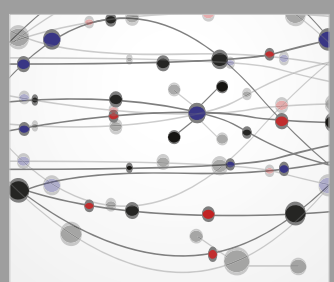

The Scientific World Journal
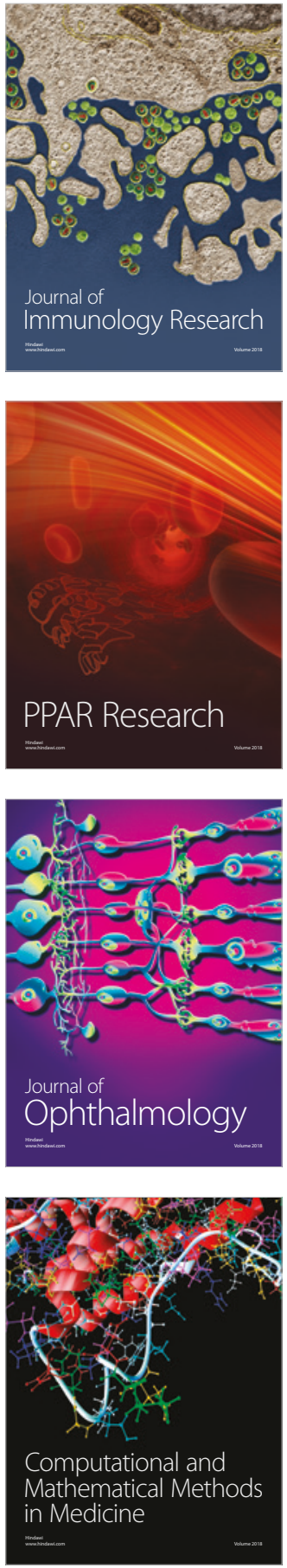

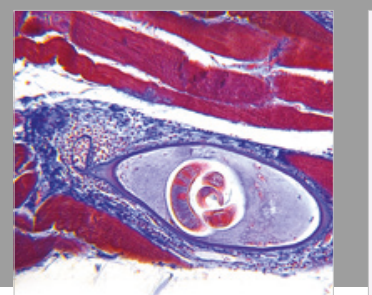

Gastroenterology Research and Practice

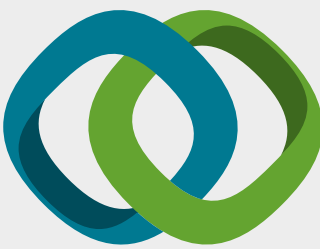

\section{Hindawi}

Submit your manuscripts at

www.hindawi.com
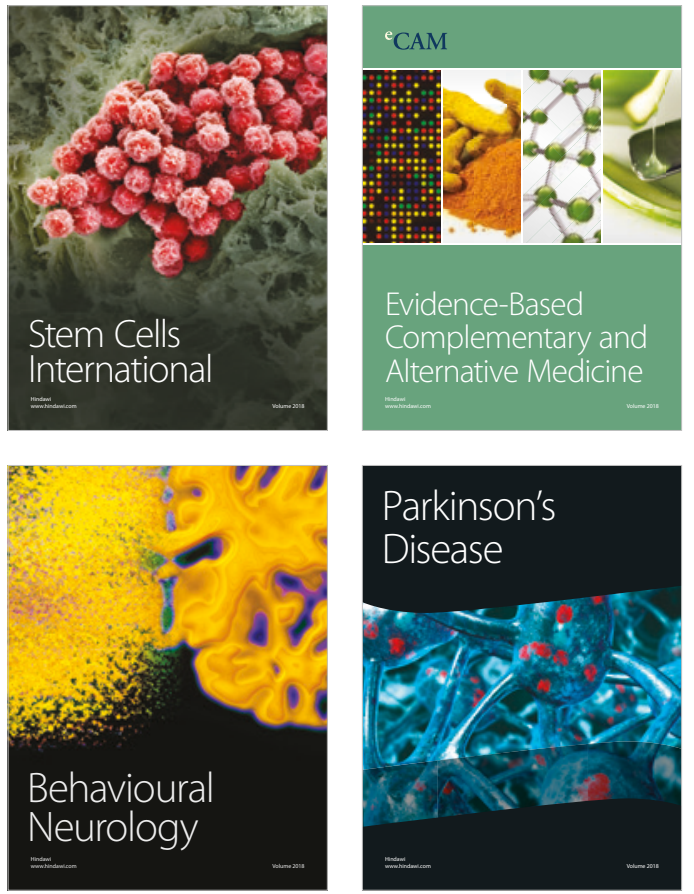

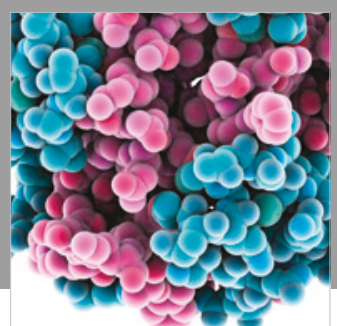

ournal of

Diabetes Research

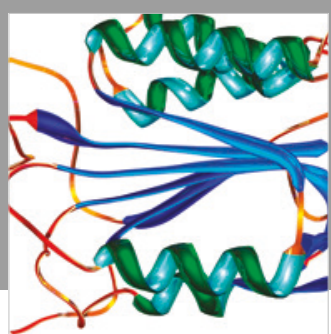

Disease Markers
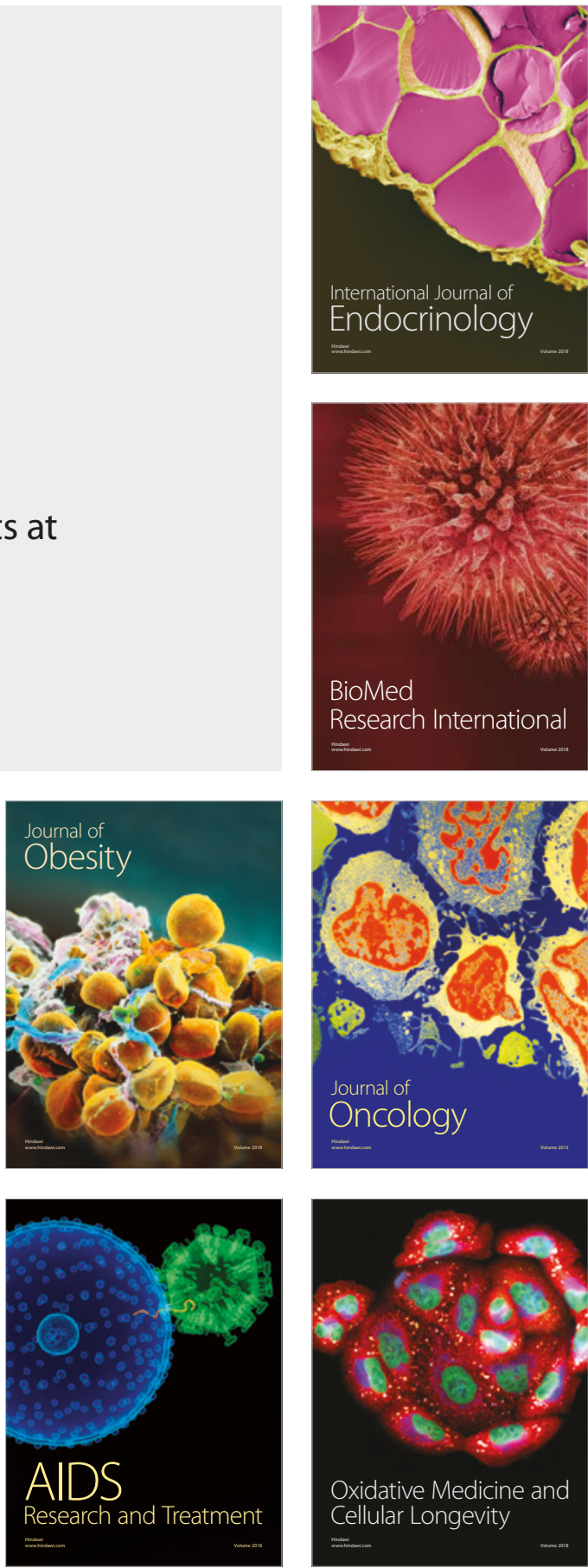